\title{
A EXTENSÃO UNIVERSITÁRIA COM FOCO NO NÚCLEO DE PRÁTICAS JURÍDICAS
}

\author{
UNIVERSITY EXTENSION FOCUSED ON LEGAL CLINICS
}

\author{
Ligia Carvalho Abões Vercelli ${ }^{1}$
}

\begin{abstract}
RESUMO
No Brasil, a maioria da população ainda não tem acesso à justiça, pois não possui recursos suficientes que permite arcar com os honorários de um advogado apesar de o art. $5^{\circ}$ inciso LXXIV da Constituição Federal de 1988 prever que o Estado deve prestar assistência jurídica integral e gratuita aos que comprovarem insuficiência financeira. Esse serviço é realizado pelas Defensorias Públicas, porém elas não conseguem atender a excessiva demanda. As faculdades de Direito por meio de convênios firmados com tal órgão e com a Ordem dos Advogados do Brasil (OAB) colaboram nesse sentido uma vez que desde 1994, o Ministério da Educação e Cultura (MEC), por meio da Portaria $n^{\circ} 1886 / 94$, fixa as diretrizes curriculares e o conteúdo mínimo do curso jurídico tornando o estágio em prática jurídica obrigatório. Este texto tem por objetivo apresentar como funcionam os Núcleos de Práticas Jurídicas (NPJs) da Pontifícia Universidade Católica de São Paulo (PUC-SP) e da Universidade Nove de Julho (Uninove), núcleos de extensão das faculdades de Direito.O trabalho fundamenta-se em autores que discutem a categoria extensão universitária tais como Freire (2010), Gurgel(1986), Sousa (2000). Utiliza-se como procedimento metodológico entrevistas semiestruturadas com doze assistidos e com doze alunos, sendo seis de cada universidade que frequentam e trabalham nos núcleos há mais de um ano. Os dados apontam que os NPJs estudados favorecem na formação acadêmica dos futuros advogados, porém atendem os assistidos fornecendo apenas a assistência jurídica necessária configurando-se assim como ação de responsabilidade social e não de compromisso social tal como propõe Paulo Freire.
\end{abstract}

Palavras-chave: Núcleo de práticas jurídicas. Extensão universitária. Universidade.

\begin{abstract}
Most of the people in Brazil do not have access to Justice due to the high cost of lawyers even though the Brazilian Constitution of 1988 states that the federal government has to provide free legal assistance to those who demonstrate financial need. This service is offered by the Public Defenders' Office (DP). However, they cannot meet the demands of the people. Therefore, Law Schools collaborate with this service through agreements signed with the DP and the Brazilian Lawyers Association (OAB). This has been made possible since 1994 by the Ministry of Education and Culture (MEC) through the Decree No. 1886/94, which established curriculum guidelines and minimum content for Law courses making legal practice internships mandatory. This paper aims to present how the Legal Clinics (NPJs) of the Pontifical Catholic University of São Paulo (PUC-SP) and of the Nove de Julho University (Uninove) work. The paper is based on authors that study the category of university extensions such as Freire (2010), Gurgel (1986), and Sousa (2000). The methodology used included semi-structured interviews with twelve clients and twelve students, six from each university. One of the criteria to select the students was that they had to attend and work in the NPJs for over a year. The data indicates that the NPJS studied enriched the academic formation of the future lawyers. However, they provided the clients with just the minimum to meet the legal assistance required. Thus, they can be defined as a social responsibility action and not as a social commitment as proposed by Paulo Freire.
\end{abstract}

Keywords: Legal Clinics. University extension. University.

\footnotetext{
${ }^{1}$ Doutora e mestre em educação pelo Programa de Pós-Graduação em Educação da Universidade Nove de Julho (Uninove). Graduada em Psicologia e em Pedagogia com especialização em Psicopedagogia. Docente do curso de Pedagogia e do Programa de Mestrado em Gestão e Práticas Educacionais (PROGEPE) da mesma universidade. Pesquisadora do Conselho Nacional de Desenvolvimento Científico e Tecnológico (CNPq). Email: vercelli.ligia@gmail.com
} 


\section{INTRODUÇÃO}

O grande perigo do assistencialismo está na violência do seu antidiálogo, que, impondo ao homem mutismo e passividade, não lhe oferece condições especiais para o desenvolvimento ou a "abertura" de sua consciência que, nas democracias autênticas, há de ser cada vez mais crítica.

Paulo Freire

A temática deste artigo está voltada para a extensão universitária com foco no Núcleo de Prática Jurídica (NPJ). Trata-se de parte de minha pesquisa de doutorado motivada a partir de experiências anteriores em projetos sociais. Mas, por que a área jurídica?

No Brasil, a maioria da população ainda não tem acesso à justiça, pois não possui recursos suficientes que permite arcar com os honorários de um advogado, apesar de o art. $5^{\circ}$ inciso LXXIV da Constituição Federal de 1988 prever que “o Estado prestará assistência jurídica integral e gratuita aos que comprovarem insuficiência de recursos".

Esse serviço é realizado pelas Defensorias Públicas, porém elas não dão conta da excessiva demanda. As faculdades de Direito por meio de convênios firmados com tal órgão e com a Ordem dos Advogados do Brasil (OAB) colaboram nesse sentido uma vez que desde 1994, o Ministério da Educação e Cultura (MEC), por meio da Portaria $n^{\circ} 1886 / 94$, fixa as diretrizes curriculares e o conteúdo mínimo do curso jurídico tornando o estágio em prática jurídica obrigatório. Assim, todas as universidades tiveram de se adequar e, desde então, oferecem atendimento gratuito à população.

Além disso, pesquisas revelam que o ensino do Direito ainda é realizado pautado em uma concepção positivista. Quanto a isso Bittar (2006) salienta que esses cursos continuam exercendo práticas pedagógicas conservadoras e tecnicistas. Os discentes ministram aulas expositivas nos moldes da educação bancária tão criticada por Paulo Freire. Dificilmente, em sala de aula, os futuros advogados relacionam teoria e prática tornando o conteúdo dissociado do contexto político, cultural e social.

Nessa mesma linha de raciocínio Oliveira e Adeodato (1996, p. 12) ressaltam:

Os cursos jurídicos mantém seu caráter bacharelesco, indiferentes às mudanças no ambiente e às novas concepções, mostrando-se inadequados não apenas para explicar e transmitir conhecimentos sobre a realidade 
jurídica brasileira como também para a preparação do corpo discente para a vida profissional.

Entende-se que os termos responsabilidade social e compromisso social se diferenciam. O primeiro surgiu na administração pautada numa ordem mercadológica e está voltado à prestação de serviço. Segundo Ashley (2003), o mundo empresarial vê na responsabilidade social uma nova estratégia para aumentar o lucro da empresa e reforçar o seu desenvolvimento.

O termo compromisso social possui nuances que ultrapassa este último. Busca-se em Paulo Freire (2010, p. 16) o que entende-se por compromisso social. Esta expressão implica que haja uma tomada de posição de todos os envolvidos; engloba decisões de todos os atores sociais e ocorre no plano das ações, da realidade concreta. Isso significa que: "A primeira condição para que um ser possa assumir um ato comprometido está em ser capaz de agir e refletir".

Para o autor, apenas os sujeitos situados no seu tempo histórico e em relação aos determinantes culturais, políticos e econômicos que condicionam seu modo de estar no mundo poderão operar mudanças e sair do conformismo, comprometendo-se em ser um sujeito da práxis. O compromisso social requer um sujeito capaz de construir um saber crítico sobre si mesmo, sobre seu mundo e sobre sua inserção nesse mundo.

De forma alguma tiramos o mérito da responsabilidade social como prestação de serviço e/ou assistência aos necessitados que vivem em situação de extrema miséria, porém, entende-se que a universidade deve ir além. O seu papel deve ser o de formar cidadãos críticos capazes de realizar ações que visem a mudança social.

As soluções meramente assistencialistas tornam as pessoas passivas e não permitem que elas tomem consciência dos fatos impossibilitando-as de participar de suas próprias ações. Nesse sentido, Freire (2003, p. 66) ressalta que "O assistencialismo [...] é uma forma de ação que rouba ao homem condições à consecução de uma das necessidades fundamentais de sua alma - a responsabilidade [...]”. Para o autor, a responsabilidade dos atos é um dado existencial do ser humano. Assim, complementa ressaltando que:

[...] No assistencialismo não há responsabilidade. Não há decisão. Só há gestos que revelam passividade e "domesticação" do homem. Gestos e atitudes. É esta falta de oportunidade para a decisão e para a 
responsabilidade participante do homem, característica do assistencialismo, que leva suas soluções a contradizer a vocação da pessoa em ser sujeito [...] (FREIRE, 2003, p. 66).

A universidade como espaço privilegiado de difusão do conhecimento e de criação de novos saberes deve mostrar à sociedade qual o seu papel, portanto, no caso dos NPJs, não cabe somente efetuar um trabalho de prestação de serviço jurídico às pessoas, mas principalmente, de levá-las a refletir que são suas ações que poderão suscitar mudanças.

Este texto está dividido em três partes. No primeiro analisa-se a categoria compromisso social universitário com foco na extensão. Em seguida apresenta-se como funcionam os NPJs das universidades pesquisadas segundo entrevistas realizadas com os respectivos coordenadores. Por último, aponta-se os dados e análises das entrevistas realizadas com os discentes que trabalham nos NPJs e com os assistidos que os frequentam.

\section{Compromisso Social Universitário}

O compromisso social universitário teve início no final da década de 1990 e se intensificou a partir de 2004, quando a expressão responsabilidade social passou a ser considerada uma ação concreta de intervenção, de mudança social e de melhoria dos indicadores socioeconômicos.

Devido à globalização, o século XXI impôs inúmeros desafios à sociedade, portanto, é necessário se modificar, se adaptar às novas formas de trabalho, de poder, de economia e de cultura. A universidade também se encontra no meio dessa transformação e, por isso, deve implantar práticas inovadoras e estimulantes de aquisição do conhecimento. Nesse sentido, a universidade socialmente responsável é aquela que, por meio do ensino, da pesquisa e da extensão consegue colocar em prática os valores aos quais dizem defender.

Pereira (2009, p. 31) salienta que a universidade atual está pautada nos princípios essenciais postulados por Humboldt que são: “[...] a formação através da pesquisa; a unidade entre o ensino e pesquisa; a interdisciplinaridade; a autonomia e a liberdade da administração da instituição e da ciência que ela produz; a relação integrada, porém autônoma, entre Estado e universidade; a complementaridade do ensino fundamental e médio com o universitário".

Para a autora, o que caracteriza a universidade atual é a associação entre ensino e pesquisa. A extensão, considerada o terceiro elemento, apareceu mais tarde, com o modelo da 
universidade norte-americana. No Brasil, a caracterização da universidade considerando os três elementos ensino, pesquisa e extensão, foi instituída somente a partir da Reforma Universitária de 1968, na Lei no ${ }^{\circ}$ 5.540/68. (PEREIRA, 2009)

Pimenta e Anastasiou (2002) ressaltam que a universidade como instituição formativa tem por finalidade o constante exercício da crítica que se sustenta no ensino, na pesquisa e na extensão, isto é, na produção do conhecimento que ocorre por meio da problematização dos saberes que foram originados no decorrer da história da humanidade, dos resultados obtidos durante a construção da sociedade e diante das novas demandas que ela impõe. Estes, por sua vez, são criados e identificados nas análises realizadas durante o processo de ensino e nas experimentações efetuadas via projetos de extensão, por meio das relações que os sujeitos estabelecem com os objetos de conhecimento.

Assim, o ensino, a pesquisa e a extensão formam o tripé de ações de compromisso social que caracterizam a universidade. A extensão teve início na Europa, no século XVIII, com a Revolução Industrial, devido às necessidades sociais da época, assumindo o papel de "preparação técnica que o novo modo de produção exigia", a partir das universidades populares. (SOUSA, 2000, p.14)

No Brasil, de acordo com Gurgel (1986), a extensão universitária é entendida sob a ótica de duas correntes. A primeira refere-se às universidades populares europeias que surgiram no século XIX, propunham uma aproximação com a população e contava com a iniciativa dos intelectuais. Assumiram grande importância em países como a Inglaterra, Alemanha, França, Bélgica e Itália.

A segunda, das universidades americanas, se pautava na prestação de serviços e era incentivada por instituições oficiais. Apareceram por volta de 1860 em função de duas experiências distintas, a saber: a extensão cooperativa ou rural e a extensão universitária ou geral.

A extensão cooperativa ou rural passou a existir nos Estados Unidos com a promulgação da Lei Smith Lever ocorrida em 1914 e se desenvolve com a participação conjunta do governo federal, dos Estados e dos municípios e cidades. Segundo Gurgel (1986, p. 60) a referida Lei assegurava:

a) caráter cooperativo dos trabalhos realizados em articulação com o colégio de Agricultura, o Departamento de Agricultura e os planos orçamentários feitos de comum acordo; 

b) ação fora dos colégios agrícolas;
c) caráter educativo do trabalho;
d) ênfase a trabalhos práticos;
e) aplicação de recursos exclusivamente em trabalhos educativos;
f) organização nos colégios, de setores próprios para as práticas de ensino de extensão.

A experiência da extensão universitária surgiu quando um grupo de professores desenvolveu um trabalho de educação de adultos. $\mathrm{O}$ reconhecimento desse tipo de extensão deu-se quando Willian Harper, dirigente da Universidade de Chicago, incluiu a educação de adultos como atividade regular da universidade, caracterizando- a como educação continuada e desligando-se da ideia de que esse tipo de educação somente seria oferecida às classes desfavorecidas, com objetivo de educá-las. Assim, a extensão foi legitimada e a "proposição incorporou cláusulas referentes a uma ação extramuros, a instrução por correspondência e outros pontos”. (GURGEL, 1986, p. 61).

Visto isto, é possível afirmar que foi a partir do modelo americano que a extensão se inicia como função da universidade na perspectiva de relacionar o ensino com a extensão. Esse modelo se baseia na religião anglicana e, por esse motivo, busca que a universidade colabore com a comunidade como uma instituição preocupada com as necessidades que esta enfrenta.

Drèze e Debelle (1983) ao comentarem sobre a universidade norte-americana ressaltam que ela aspira levar a sociedade ao progresso. Quanto a isso, comentam:

O que importa para uma nação é a existência de uma relação muito estreita, entre seus elementos progressivos de todos os gêneros, de tal sorte que o estudo influencie o lugar público e reciprocamente. As universidades são os principais agentes desta fusão de atividade progressivas num instrumento eficaz do progresso. Elas não são, naturalmente, os únicos agentes, mas, hoje, é, um fato que as nações progressivas são também aquelas onde as universidades são florescente. (DRÈZE e DEBELLE, 1983, p. 64)

Para os autores, é por meio da sociedade que a universidade dará sua contribuição e esta deverá ocorrer no plano de valores intelectuais, deve ser uma educação "útil" tanto para estudantes quanto para pesquisadores. Salientam que os estudantes são seres interessados pela vida em todas as suas manifestações, por isso não se deve isolar a vida intelectual da ação, pois a inteligência não se desenvolve no vazio, ela busca se apoiar na relação existente entre 
teoria e prática. Os autores apontam que as universidades devem encorajar a pesquisa fundamental nas disciplinas de base e a pesquisa interdisciplinar que ocorre fora da universidade e necessária para renovar a reflexão dos pesquisadores universitários.

Assim, o papel da universidade com centro de progresso incita docentes e discentes a fazerem pesquisas sobre a sociedade e para tal faz-se necessário recorrer às contribuições das demais áreas do conhecimento. Quanto a isso, os autores comentam:

[...] Compreendendo que seus estudantes trabalharão, durante trinta ou quarenta anos, numa sociedade em perpétua evolução, ela os preparará para uma vida de autoeducação permanente, em vez de querer dotá-los de um saber definitivo para utilização permanente. As necessidades claramente reconhecidas e, sobretudo, previsíveis da sociedade, as orientações mais recentes da ciência, inspirarão, então, os programas universitários. (DRÉZE E DEBELLE, 1983, p. 70)

Essas palavras reafirmam que o conhecimento adquirido na universidade terá sentido se fizer consonância com os problemas enfrentados pela sociedade, pois estes são dinâmicos e merecem ser discutidos a todo o momento. Assim, a educação universitária deve esclarecer as ideias gerais e estudar a viabilidade de sua aplicação a casos reais. E no Brasil, como iniciou a extensão?

Gurgel (1986) salienta que a extensão, na história das universidades brasileiras, ocorre em três períodos. O primeiro se estende de 1911 a 1930 e é considerado o período das experiências pioneiras, realizadas pela criação da universidade Livre de São Paulo e pela Fundação da Escola Superior de Agricultura e Veterinária de Viçosa-MG, baseada no modelo americano. É na universidade Livre de São Paulo que surgem as primeiras ideias sobre cursos de extensão como forma de prestação de serviços.

Cunha (2007) aponta que a universidade livre de São Paulo promovia conferências semanais gratuitas abertas a quem quisesse participar. De dezembro de 1914 a junho de 1917 foram realizadas 107 "lições públicas" sobre diversos assuntos, a saber: o fogo sagrado na Idade Média, grandes viagens e grandes viajantes do Brasil, importância e progresso da otorrinolaringologia, instituições complementares do Código Civil etc. O autor salienta que esses cursos não despertavam o interesse das classes populares, eram totalmente desvinculados das necessidades reais da população e, por isso, encerraram suas atividades em 1917. A primeira experiência efetiva de extensão ocorre em 1926, em Viçosa (MG), com a 
implantação da Escola Superior de Agricultura e Veterinária, cujos professores vieram dos Estados Unidos.

O segundo período, segundo Gurgel (1986), pautado na corrente das universidades europeias, se estende de 1930 a 1968, e a extensão é vista como política, pois o que a caracteriza são as ideias e ações dos movimentos estudantis. A década de 1930, segundo Frantz e Silva (2002) foi marcada por muitas modificações na estrutura do Estado e, principalmente, nas políticas educacionais. Houve, nessa época, uma maior conscientização dos problemas educacionais e, entendia-se que a reforma da sociedade se daria mediante reforma da educação e do ensino. O termo extensão apareceu pela primeira vez na legislação educacional, em 1931 no primeiro estatuto das universidades brasileiras (Decreto Federal de 11 de abril de 1931).

Segundo Sousa (2000, p. 16) a extensão, nesse documento, é entendida como: “[...] organismo de vida social da universidade, sendo reconhecida pelo oferecimento de cursos e conferências de caráter educacional". Vale lembrar que no final desse período foi criado, em 11 de julho de 1967, o projeto Rondon que tinha como objetivo levar estudantes universitários voluntários ao interior do país, para que realizassem trabalhos em comunidades carentes e isoladas. O projeto Rondon é uma iniciativa do governo brasileiro, coordenada pelo Ministério da Defesa, em colaboração com a Secretaria de Educação Superior do Ministério da Educação (MEC).

O terceiro período, de acordo com Gurgel (1986) se estende de 1969 a 1976 e é entendido como a época de maior institucionalização de extensão universitária, pois as atividades de extensão passam da perspectiva da difusão do conhecimento para o de inserção na realidade sócio econômica, política e cultural do país, buscando respostas para que contribuíssem com a mudança social. A extensão foi consolidada pela Reforma Universitária por meio da Lei $\mathrm{n}^{\mathrm{o}} 5.540 / 68$. Essa Lei, em dois dos seus artigos estabelece:

Art. 20 - As universidades e as IES estenderão à comunidade, sob forma de cursos e serviços especiais, as atividades de ensino e os resultados da pesquisa que lhe são inerentes.

Art. 40 - As instituições de ensino superior, por meio de suas atividades de extensão, propiciarão aos corpos discentes oportunidades de participação em programas de melhoria das condições de vida da comunidade e no processo geral de desenvolvimento. 
No entanto, mesmo com essa Lei a universidade não foi capaz de modificar a cultura intelectualista, pautada no ensino e na pesquisa. Dessa forma, essas duas funções continuaram por ser privilegiadas e, a extensão universitária, era entendida como uma atividade menos importante, aceita pela minoria dos docentes e mesmo assim desenvolvidas de forma fragmentada. (PIMENTA e ANASTASIOU, 2002).

Para o Ministério da Educação e da Cultura (MEC) a extensão é entendida como: "meio através do qual a universidade atende a outras instituições e a população, e por outro lado, recebe retroalimentação para o ensino e a pesquisa". Partindo da mesma orientação o Conselho dos Reitores das Universidades Brasileiras (CRUB) definiu as atividades de extensão segundo três critérios, a saber: prestação de serviços à comunidade, realimentação da universidade e a integração de ambas.

Segundo o Plano Nacional de Extensão Universitária (2001, p. 3), foi no final da década de 1980 que o compromisso social das universidades públicas brasileiras passou a ser questionado e reelaborado. "Do assistencialismo passou-se ao questionamento das ações desenvolvidas pela extensão; de função inerente à Universidade, a Extensão começou a ser percebida como um processo que articula o ensino e a pesquisa, que organiza, assessorando, os movimentos sociais que estavam surgindo".

Nesse período iniciam-se, no âmbito acadêmico, político e social, discussões referentes à universidade cidadã e a necessidade de fornecer aos alunos uma formação integral. Ocorre assim uma parceria entre o poder público, a universidade, a comunidade e as empresas a fim de proporcionar uma aproximação entre universidades e comunidades carentes do Estado de São Paulo.

Nessa época, as ideias e práticas de Paulo Freire fundamentam as práticas referentes à extensão universitária. Discute-se aindissociabilidade entre ensino, pesquisa e extensão; a extensão como via de mão dupla, a extensão que deve produzir conhecimento pautada em uma realidade concreta e a extensão como comunicação.

A extensão entendida como comunicação, segundo Freire (2010) deve constituir um diálogo entre a universidade e a sociedade, pois para ele sem a comunicação, a universidade não possibilita à comunidade as condições necessárias para que esta assuma suas responsabilidades impossibilitando, dessa forma, o crescimento pessoal.

Em 20 de dezembro de 1996, foi votada a Lei de Diretrizes e Bases da Educação Nacional (LDBEN) de número 9346/96 que oferece melhor formato à atividade de extensão 
universitária, ao cobrar das universidades ações de transformação social, porém a prática ainda é muito fragilizada, porque algumas instituições realizam atividades completamente afastadas das comunidades onde estão inseridas. (SOUSA, 2000)

A Constituição de 1998 no artigo 207 reforça a necessidade da extensão apontando que as universidades devem ser regidas pelo "princípio de indissociabilidade entre ensino, pesquisa e extensão", isto é, não apresenta nada de novo sobre o tema.

No mesmo ano, o Fórum Nacional de Pró-Reitores de Extensão das Universidades Públicas Brasileiras elabora o Plano Nacional de Extensão Universitária. Esse Plano aponta a extensão universitária numa perspectiva cidadã.

A Lei 10.861, promulgada em 14 de abril de 2004, considera o compromisso social universitário como uma das dez dimensões do Sistema Nacional de Avaliação da Educação Superior (SINAES). De acordo com esta lei, as universidades devem acrescentar aos seus objetivos: o Plano de Desenvolvimento Institucional (PDI), uma política para o ensino, pesquisa, pós-graduação e extensão; a comunicação com a sociedade; as políticas de pessoal; a organização e gestão da instituição; o funcionamento dos colegiados; a infraestrutura física; ao planejamento e à avaliação; as políticas de atendimento aos estudantes e sustentabilidade financeira (BRASIL, 2007).

No que concerne à extensão, o artigo $3^{\circ}$ item III da referida lei esclarece que: "a responsabilidade social da instituição, considerada especialmente no que se refere à sua contribuição em relação à inclusão social, ao desenvolvimento econômico e social, à defesa do meio ambiente, da memória cultural, da produção artística e do patrimônio cultural". Com essa lei notamos um certo avanço no que se refere às atividades que a universidade poderá desenvolver no que se refere à extensão.

Assim, as instituições de ensino superior, sejam elas privadas ou públicas buscam desenvolver projetos extensionistas que vêm ao encontro das necessidades encontradas pela comunidade na qual está inserida. Dessa forma, a universidade tenta cumprir um de seus papéis que é contribuir na construção de novas bases societárias atendendo o que dispõe o Plano Nacional de Extensão Universitária (2001) que a caracteriza como: 
oportunidade de elaboração da práxis de um conhecimento acadêmico. No retorno à universidade, docentes e discentes trarão um aprendizado que, submetido à reflexão teórica, será acrescido àquele conhecimento. Esse fluxo, que estabelece a troca de saberes sistematizados, acadêmico e popular, terá como consequências a produção do conhecimento resultante do confronto com a realidade brasileira e regional, a democratização do conhecimento acadêmico e a participação efetiva da comunidade na atuação da universidade. Além de instrumentalizadora deste processo dialético de teoria/prática, a extensão é um trabalho interdisciplinar que favorece a visão integrada do social. (PLANO NACIONAL DE EXTENSÃO UNIVERSITÁRIA, 2001, p. 6)

A extensão enquanto compromisso social da universidade deverá ser entendida, nos dias atuais, como nova cultura institucional. Junto com órgãos do governo, com ONGs, outra instituições do terceiro setor, a universidade poderá estabelecer ações para enfrentar os desafios que nossa sociedade apresenta.

Isso significa que cada instituição de ensino superior deveria estar engajada com outras universidades e outros órgãos para agirem no que se referem a situações cruciais que a população enfrenta tais como desenvolvimento econômico, as discriminações de todo tipo, a péssima qualidade dos serviços públicos, principalmente nas áreas da educação e da saúde. Nesse sentido, compromisso social universitário deveria ter um caráter progressista e transformador visando a construção de uma sociedade mais justa onde as pessoas vivam com dignidade.Diante dessas considerações, entende-se extensão como:

Todas as atividades que ocorrem extra sala de aula, dentro ou fora da universidade, via educação não formal. São atividades atreladas ao ensino e à pesquisa que devem ser exercidas de acordo com as demandas da sociedade por meio de intervenção social e difusão de conhecimento na busca de propostas que minimizem os desafios enfrentados pela sociedade. Essas ações compreendem diferentes eixos, a saber: atividades de cunho acadêmico, científico e cultural, atividades de prestação de serviço, atividades de assessorias, consultorias e supervisões, atividades de educação continuada e projetos sociais cujos objetivos são voltados às necessidades específicas da comunidade. Tratam-se, assim, de atividades que exigem que ela [a universidade] se comunique com a sociedade, pois é por meio desse diálogo que a universidade poderá entender os reais interesses da sociedade e produzir mais conhecimentos que atendam às suas necessidades (VERCELLI, 2012, p. 61).

Segundo Fraga (2010, p. 28) uma universidade socialmente compromissada necessita cumprir as seguintes tarefas, a saber: "transmitir o saber, qualificar o profissional e formar o caráter, enfim, “construir” o cidadão. [...] Significa preparar pessoas capazes de se autogerir, 
de exercer o papel de sujeitos autônomos, livres, participativos e comprometidos". Nesse sentido, a autora complementa que:

[...] o ensino sem a extensão torna-se uma prática abstrata e livresca; a pesquisa sem extensão foge a seu objetivo de oferecer à sociedade respostas e conhecimentos necessários ao enfrentamento dos problemas reais. Enfim, a extensão descolada da pesquisa e do ensino, tende a ser uma prática baseada no senso comum, com fortes possibilidades de se resvalar para a filantropia, para a caridade e para um fazer legitimador da desigualdade e da discriminação em que perdem todos: pesquisadores, alunos, comunidade e sociedade. (FRAGA, 2010, p. 31)

Atualmente, a extensão é uma exigência do processo formativo; portanto, tem de estar presente no exercício pedagógico do trabalho universitário. Toda instituição de ensino superior poderia desenvolver projetos de extensão, pois é por meio deles que os discentes constroem uma nova consciência social.

Dessa forma, o compromisso social da universidade está em formar profissionais que tenham consciência do papel que irão exercer no contexto social e que utilizem o seu potencial criativo na transformação da realidade em que estão inseridos, buscando sempre o bem-estar da população dentro dos limites impostos por essa realidade.

Nesse sentido, Georgen (2003, p. 120) afirma que a formação como parte inerente do compromisso social, vai além da aquisição do conhecimento e habilidades que perpassam o exercício da profissão, ela deve familiarizar os estudantes com temas contemporâneos que afetam a comunidade nacional e internacional. Para o autor, o compromisso social da universidade “[...] não é outra coisa senão o sentido social da instituição acadêmica. Da instituição acadêmica em todas as suas dimensões, tanto no que diz respeito às funções de pesquisar e ensinar, quanto no que se refere aos agentes envolvidos nesse processo, isto é, professores, alunos e funcionários [...]”.

O compromisso social universitário pressupõe ensinar os discentes a pensar o momento presente e como proceder diante dos dilemas apresentados por nossa sociedade. Para tanto, a teoria discutida em sala de aula deve estabelecer relação com a prática e isso poderá ser feito também por meio de ações extensionistas propostas pela universidade. Porém, essas ações devem ser humanizadoras, ir ao encontro das necessidades da comunidade e, para isso, o compromisso social das universidades deve contemplar ações concretas, que 
configurem a lógica da mudança social, do exercício da cidadania, da coerência entre discurso e ação.

\section{Os núcleos de práticas jurídicas da PUC-SP e da Uninove}

O Escritório Modelo "Dom Paulo Evaristo Arns" - Unidade de Prática Jurídica surgiu em 1999 com o objetivo de disponibilizar serviços jurídicos gratuitos à população desfavorecida social e economicamente. Desenvolve projetos de natureza social e individual e atua em diferentes comunidades na defesa de causas coletivas e individuais, fomentando políticas públicas, especialmente relacionadas à "minorias" sociais, por meio de um diálogo direto com o Poder Público. Possui convênio com os seguintes órgãos: Defensoria Pública do Estado de São Paulo, Secretaria Especial de Direitos Humanos da Presidência da República, Instituto Pólis e com o Instituto de Mediação e Arbitragem do Brasil (IMAB).

Tem por objetivo orientar, assessorar, defender, mediar e postular em juízo a favor da população socialmente vulnerável. Além disso, busca ampliar o acesso da população à justiça e colaborar na formação acadêmica dos estudantes da PUC-SP comprometidos com a função social do Direito. Em um trabalho que inclui prevenção, tutela coletiva e individual e atuação extrajudicial, o Escritório Modelo já atendeu, desde a sua criação em 1999, mais de 50 mil pessoas e suas famílias. (fonte: folder fornecido pela instituição - Escritório Modelo "Dom Paulo Evaristo Arns" - Núcleo de prática jurídica - Faculdade de Direito PUC-SP).

O Escritório Modelo atende ações individuais e coletivas. Entre eles estão os projetos de orientação jurídica e assessoria aos moradores da Favela do Moinho, Favela do Amadeu e da Comunidade Jurubatuba localizadas respectivamente nas regiões central e sul da cidade de São Paulo e um trabalho de orientação voltado à legalização e à defesa de Rádios Comunitárias, destinado a cerca de oitenta associações.

No que se refere à moradia, o Escritório Modelo atende todas as regiões da cidade de São Paulo, cerca de 30 comunidades, por volta de 2.000 famílias. Eles mantêm contato com o movimento de moradia, realizam cadastro dos moradores das comunidades assistidas, promovem Jornadas de Moradia.

Quanto ao projeto de comunicação - rádio comunitária - são 187 rádios e o Escritório oferece assessoria a 117 delas. Existe um grupo de estudos da rádio comunitária de Heliópolis e da rádio Cantareira. Além disso, possui ações em parceria com o Intervozes - Coletivo 
Brasil de Comunicação Social, pois $25 \%$ da programação precisa de ação para ser regulamentada.

O Escritório Modelo realiza as seguintes atividades de caráter social: Balcão de Direitos que tem por objetivo informar a população sobre direitos e deveres e o Projeto Pacificar, criado para divulgar e aplicar a mediação como forma de resolver impasses antes da entrada de um novo processo no Poder Judiciário. Os atendimentos deste projeto são feitos tanto no Escritório Modelo quanto em favelas e comunidades nas quais os profissionais e estagiários também trabalham como multiplicadores, divulgando a mediação como instrumento de solução de conflitos.

O Escritório trabalha com o conceito de "advogado popular" que atua vinculado ao terceiro setor. Esse advogado tem uma função educativa, ou seja, ele esclarece a população não apenas os direitos, mas também os deveres de cada um. Em 14 anos de existência, o Escritório já atendeu mais de 50.000 pessoas em toda São Paulo.

O Escritório Modelo conta com o Balcão de Direitos que possui parceria com a Secretaria de Direitos Humanos. Ele consiste em atendimento à comunidade. É uma forma de potencializar o trabalho do núcleo. Diversos temas referentes aos Direitos Humanos são discutidos e cartilhas, vinhetas são elaboradas e fornecidas às comunidades. Os temas discutidos são, muitas vezes, sugeridos pelos moradores. Apenas 10 estagiários participam e é pouco em função da demanda existente. A ideia é abrir para estagiários de outas universidades. O projeto, para que tal ação seja efetuada, já foi elaborado, mas precisa ter aprovação da PUC-SP.

O NPJ da Uninove iniciou suas atividades no ano de 2003 disponibilizando serviços jurídicos gratuitos à população desfavorecida social e economicamente, quando os 50 alunos das primeiras turmas do curso de Direito cursavam o $7^{\circ}$ semestre. Nessa época foram atendidas 300 causas. Com o passar do tempo o NPJ sofreu modificações para melhor se adequar às especificidades do curso, sempre visando a melhoria dos atendimentos à população. Atualmente, a Uninove possui quatro NPJs, um em cada unidade.

Em 2010, a Uninove firmou um convênio com o Tribunal de Justiça de São Paulo com objetivo de facilitar a resolução conflitos nas áreas cível e de família. Trata-se de uma Unidade Avançada de Atendimento Judiciário (UAAJ) que receberá pedidos de alimentos e realizará audiências de conciliação. O centro foi inaugurado dia 30 de novembro de 2010 e localiza-se na Rua Vergueiro, 831. Iniciou suas atividades em março de 2011. A conciliação 
tem como objetivo a tentativa de um acordo amigável entre as partes, antes do ajuizamento da ação ou durante um processo judicial. É um meio de resolução de conflitos em que as partes confiam a uma terceira pessoa (o conciliador) a função de aproximá-las e orientá-las na construção de um acordo. Para isso, alunos do Curso de Direito são preparados pelo próprio Tribunal de Justiça, que homologará os acordos celebrados.

Os atendimentos ocorrem diariamente e não há limitação quanto ao bairro ou região, desde que os assuntos abordados sejam da área de família ou cível e que o valor em discussão, se houver, não ultrapasse 40 salários mínimos vigentes. Este atendimento não está limitado exclusivamente às pessoas que recebem até três salários mínimos como ocorre nos atendimentos do contencioso. Qualquer pessoa que queira resolver seus problemas jurídicos, sem ter de esperar a morosidade do judiciário poderá recorrer à conciliação desde que a outra parte esteja de acordo.

\section{Alguns dados obtidos na pesquisa}

Os estudantes que trabalham no contencioso do NPJ da PUC-SP e da Uninove atendem causas individuais. O trabalho consiste em atender os assistidos, elaborar as peças, participar de audiências simuladas no fórum, ir às delegacias (no caso do estagiário de Direito penal) e à Defensoria Pública. Todas as peças elaboradas são corrigidas pelo professor, refeitas e/ou alteradas, se necessário, assinadas pelo advogado orientador e, por último, encaminhadas ao fórum. Na PUC-SP existe o departamento de projetos sociais que atende causas coletivas, principalmente, aquelas voltadas às questões de moradia. Os alunos vão às comunidades e realizam seus trabalhos inseridos nesses locais.

Quanto a isso, um estagiário da Uninove aponta que não considera o NPJ um projeto social, pois para se configurar como tal, os alunos deveriam ir à comunidade e tentar entender o porquê da fome, da violência e da miséria. A Uninove atende apenas o contencioso, isto é, causas individuais. Na PUC-SP, no que se refere ao contencioso, a situação não é diferente. São os assistidos que procuram o "Escritório Modelo" e para chegar nele, tiveram de ser encaminhados pela Defensoria Pública. Talvez muitas pessoas fiquem sem atendimento, pois não têm condições financeiras e/ou de saúde para se deslocar até os NPJs. A fim de resolver esse problema, entende-se que os coordenadores, advogados e discentes de ambos os NPJs estudem uma forma de atender também algumas causas individuais na própria comunidade. 
Os estagiários das duas universidades relatam que é gratificante trabalhar no NPJ, pois estão em contato direto com o assistido e, assim, aprendem o ofício do advogado uma vez que realizam todas as atividades deste profissional. Em escritórios de advocacia não teriam essa oportunidade. Dessa forma, ressaltam que trabalhar no núcleo é extremamente relevante acadêmica e profissionalmente.

Os estagiários do NPJ da Uninove sentem falta de um apoio interdisciplinar, principalmente de um psicólogo e de um assistente social. Relatam que muitas vezes os casos ultrapassam questões jurídicas e que eles ficam perdidos sem essa orientação. Como possível solução, entende-se que seja necessário uma articulação com os cursos de Psicologia e de Ciências Sociais a fim de buscar suprir essa necessidade.

Apesar de o "Escritório Modelo" contar com uma psicóloga e com uma socióloga a situação não se torna mais confortável. Em função da demanda existente, essas profissionais relatam que é impossível dar conta de atender todos os assistidos, interferindo apenas nos casos de maior urgência. Além disso, a rotatividade de alunos no NPJ da PUC-SP inviabiliza um trabalho contínuo. Nessa instituição, os alunos podem permanecer no escritório por apenas um ano e, em função disso, o quadro de estagiários é modificado constantemente. $\mathrm{Na}$ Uninove, o aluno pode permanecer no núcleo durante dois anos consecutivos, ou seja, enquanto cursam do $7^{\circ}$ ao $10^{\circ}$ semestres de Direito.

Outro dado relatado pelos estagiários dos núcleos das duas universidades é a ausência de reuniões com os coordenadores para que eles possam discutir os diferentes casos atendidos e ouvir os dos colegas. Entende-se que essas reuniões seriam de grande valia uma vez que é por meio do diálogo e da toca de informação que se constrói o conhecimento e se discuta as reais necessidades da comunidade.

Podemos perceber também a relação existente entre educação formal e educação não formal. Caracterizamos o Núcleo de Práticas Jurídicas como um espaço educativo institucional não formal que se complementa ao da sala de aula. Os próprios estagiários disseram que, nos núcleos eles têm oportunidade de aprofundar conhecimentos aprendidos em sala de aula e que, muitas vezes, aprendem primeiro nesses espaços em função das causas que devem analisar para, futuramente, estudarem de maneira formal.

Quanto aos assistidos que procuram os NPJs das duas universidades, a maioria é do sexo masculino e a natureza da causa está voltada para a pensão alimentícia dos fillhos. No caso das mulheres encontramos também causas voltadas à violência doméstica. Quanto a isso, 
observamos um dado importante: o da luta das mulheres. São elas que, em princípio, procuram os NPJs a fim de obter, perante a justiça, a pensão alimentícia cujos filhos têm direito. Os homens que procuram os núcleos (nossos entrevistados) o fazem porque foram intimados.

Todos os assistidos ressaltam que são atendidos respeitosamente nos núcleos. Na PUC-SP, o atendimento ocorre em dia previamente determinado por ordem de chegada e, na Uninove, com hora marcada. Dessa forma, eles não enfrentam fila e chegam a comparar o atendimento recebido nos NPJs com o de alguns órgãos públicos, principalmente hospitais e/ou Unidades Básicas de Saúde (UBS). Ressaltam que se fossem atendidos nesses locais como são nos NPJs seria muito bom. Apontam, portanto, para questões referentes à cidadania.

\section{CONSIDERAÇÕES FINAIS}

Este texto teve por objetivo apontar como é realizado o trabalho nos Núcleos de práticas Jurídicas da Universidade Nove de Julho e da Pontifícia Universidade Católica de São Paulo a fim de analisar se eles exercem ações de responsabilidade social ou de compromisso social.

O histórico da extensão universitária leva-nos a entender que as práticas atuais devem estar pautadas na extensão como comunicação tal como aponta Paulo Freire, porém os resultados obtidos revelam que os NPJs ainda realizam trabalho voltado à prestação de serviço no qual não existe relação com demais profissionais e consciência crítica por parte dos discentes e comunidade.

Alguns estagiários apontam para esse fato a ponto de não caracterizarem os NPJs como projetos sociais. Para eles o trabalho deveria ser realizado também na comunidade para que possam que possam entrar em contato com as dificuldades vividas pelos assistidos.

Os discentes entendem que o trabalho realizado nos NPJs é fundamental para a formação acadêmica uma vez que durante as aulas torna-se mais difícil, pois segundoMarchese (2006, p. 115) o currículo dos cursos jurídicos no Brasil não tem por tendência fornecer uma formação interdisciplinar. Segundo ele, com exceção da “[...] legislação educacional aconselhando aos cursos a observação da interdisciplinaridade, não há qualquer outro dispositivo que disponibilize condições para a efetiva implantação de um 
currículo que agregue outros campos de conhecimento [...]”. Assim, de acordo com o autor, um ensino multidisciplinar não é o foco dos cursos de Direito e sim a transmissão do conhecimento jurídico específico.

Diante desse fato, vale repensar a formação do advogado, principalmente no que se refere ao trabalho realizado nos núcleos. Entende-se que esses espaços deveriam promover a reflexão e ensinar os discentes a ter uma escuta mais apurada das problemáticas trazidas pelos assistidos.Nesse sentido, vê-se como necessário uma ação interdisciplinar envolvendo profissionais da psicologia e das ciências sociais. Da forma como se encontram os NPJs caracterizam-se como ação de responsabilidade social e não de compromisso social tal como se entende. Não tira-se o mérito do trabalho do modo como é realizado, mas a universidade tem por função social formar cidadãos críticos que possam vislumbrar uma sociedade mais justa e igualitária.

\section{REFERÊNCIAS}

ASHLEY, Patrícia Almeida. Responsabilidade Social nos Negócios. São Paulo: Saraiva, 2003.

BITTAR, Eduardo Carlos Bianca. Estudos sobre o ensino jurídico: pesquisa, metodologia, diálogo e cidadania. São Paulo: Atlas, 2006.

BRASIL. Ministério da Educação e Cultura (MEC) disponível em: <prouniportal.mec.gov..br> - acesso em: 9 Ago. 2013.

Ministério da Educação e Cultura (MEC) disponível em: <portal.mec.gov.br>. Acesso em: 9 Ago. 2013.

Plano Nacional de Extensão Universitária - Fórum de Pró-Reitores de Extensão das Universidades Públicas Brasileiras. Ilhéus. Bahia: Editus, (Coleção Extensão Universitária), 2001. 
. Ministério da Educação e Cultura - MEC. Lei n ${ }^{\circ}$ 10861, de 14 de abril de 2004. Brasília: SINAES. Disponível em www.mec.gov.br/sesu - acesso em 9 de agosto de 2013.

. Plano Nacional de Extensão. Disponível em www.mec.gov.br/sesu. Acesso em 10 de outubro de 2010.

CUNHA, Luiz Antônio. A universidade temporã: o ensino superior, da Colônia à Era Vargas. São Paulo. UNESP, 2007.

DRÈZE, Jacques; DEBELLE, Jean. Concepções da universidade. Tradução de Francisco de Assis Garcia e Celina Fontenele Garcia. Fortaleza: Edições Universidade Federal do Ceará, 1983.

FRAGA, Nívea Maria. Responsabilidade Social de instituições de ensino superior. Diálogos e Ciência. Revista da rede de ensino FTC. Ano IV. n. 13, junho de 2010, p. 21 - 35.

FRANTZ, Walter; SILVA, Enio Waldir. As funções sociais da universidade: o papel da extensão e a questão das comunitárias. Ijuí. Rio Grande do Sul: Inijuí, 2002.

FREIRE, Paulo. Professora sim tia não: cartas a quem ousa ensinar. São Paulo: Olho D’Agua, 2003.

. Extensão ou Comunicação. 14. ed. Rio de Janeiro: Paz e Terra, 2010.

GEORGEN, Pedro, Universidade e Responsabilidade Social. In: LOMBARDI, José Claudinei. Temas de Pesquisa em Educação. Campinas: Autores Associados, p. 101 a 120, 2003.

GURGEL, Roberto Mauro. Extensão Universitária: comunicação ou domesticação. São Paulo:Cortez/Autores Associados/EUFC, 1986.

A construção do Conceito de Extensão Universitária na América Latina. In. FARIA, Dóris Santos de. (org.). Construção Conceitual da Extensão Universitária na América Latina. Brasília. UnB, 2001. 
MARCHESE, Fabrizio. A crise do ensino jurídico no Brasil a as possíveis contribuições da educação geral. Dissertação de mestrado. Universidade Estadual de Campinas. UNICAMP, 2006.

OLIVEIRA, Luciano; ADEODATO, João Maurício. O estado da arte da pesquisa jurídica e sócio-jurídica no Brasil. Brasília: Conselho da Justiça Federal, Centro de estudos judiciários, 1996.

PEREIRA, Elisabete Monteiro de Aguiar. A Universidade da modernidade nos tempos atuais. Avaliação da Educação Superior. Universidade de Sorocaba: São Paulo, v. 14, nº 1, p. 29-52, março de 2009.

PIMENTA, Selma Garrido; ANASTASIOU, Léa da Graças Camargo. Docência no ensino superior. São Paulo: Cortez, 2002.

SOUSA, Ana Luiza Lima. A História da Extensão Universitária. Campinas: Alínea, 2000.

VERCELLI, Ligia de Carvalho Abões. Projetos sociais desenvolvidos em universidades da cidade de São Paulo: mapeamento e análise.Tese de Doutorado. Programa de Pós-Graduação em Educação. Universidade Nove de Julho. São Paulo, 2012.

. Projetos sociais na universidade brasileira: vozes e ação pela cidadania. Jundiaí:

Paco Editorial, 2013.

RECEBIBO EM: 12/09/2013

APROVADO PARA PUBLICAÇÃO EM: 14/09/2015 